\title{
Creation of a Knowledge Society via the Use of Mobile Blog: A Model of Integrated Meaningful Hybrid E-training
}

\author{
Rosseni Din ${ }^{1}$, Helmi Norman ${ }^{1}$, M. Faisal Kamarulzaman ${ }^{2}$, Parilah M. Shah ${ }^{1}$, Aidah Karim ${ }^{1}$, Nor Syazwani Mat \\ Salleh $^{1}$, M Shanudin Zakaria ${ }^{3} \&$ Khairul A Mastor ${ }^{4}$ \\ ${ }^{1}$ Faculty of Education, Universiti Kebangsaan Malaysia, Selangor, Malaysia \\ ${ }^{2}$ Faculty of Economy and Business, Universiti Kebangsaan Malaysia, Selangor, Malaysia \\ ${ }^{3}$ Faculty of Technology and Information Science, Universiti Kebangsaan Malaysia, Selangor, Malaysia \\ ${ }^{4}$ Center for General Studies, Universiti Kebangsaan Malaysia, Selangor, Malaysia \\ Correspondence: Rosseni Din, Faculty of Education, Universiti Kebangsaan Malaysia, 43600 UKM Bangi, \\ Selangor, Malaysia. Tel: 60-3-8921-7102. E-mail: rosseni@ukm.my
}

Received: September 20, 2012 Accepted: November 7, $2012 \quad$ Online Published: November 30, 2012

doi:10.5539/ass.v8n16p45

URL: http://dx.doi.org/10.5539/ass.v8n16p45

\begin{abstract}
Mobile blog or "moblog" provides a coherent purpose for strategic educational change through lifelong education and the creation of a knowledge society. Many studies have been conducted on using conventional blogs in teaching and learning yet only few have focused on moblogs. Moblogs allow trainers to empower themselves through the acquisition of both explicit and tacit knowledge. Thus, this study aims at designing, developing and implementing moblogs as a platform for a new hybrid e-training approach, which was tested to generate a two-stage model for meaningful hybrid e-training. The data were collected from 213 Information Communication Technology (ICT) trainees which were subsequently tested using confirmatory factor analysis with AMOS 7.0 to obtain the best-fit measurement model for an integrated meaningful hybrid e-training model using moblogs. The results revealed that: (i) hybrid e-training influenced the achievement of meaningful e-training; (ii) learning styles influenced the acceptance of hybrid e-training; and (iii) learning styles preferences influenced the achievement of meaningful e-training.
\end{abstract}

Keyword: mobile blog, WordPress, confirmatory factor analysis

\section{Introduction}

Mobile blog or "moblogs" in this study is a media that is used to support the hybrid e-training method. Scholars have envisioned blogs as a space where discourse can occur among learners, between learners and instructors, as well as between learners and the larger Internet community. Moblogs can be applied as tools for knowledge management (KM), where individuals or organizations consciously and comprehensively gather, organize, share, and analyse its' internal knowledge in terms of resources, documents, and "people skills". According to Santosus and Surmacz (2001), KM is the process through which organizations generate value from their intellectual and knowledge-based assets. Most often, generating value from such assets involves sharing them among employees, departments, and even with other institutions, in an effort to devise best practices. In this study, assets constituted the communities of practice involving teacher trainees.

It is important to note that the definition of KM does not include the aspect of technology - while KM is often facilitated by e-training technology, technology by itself is not KM. Therefore, we need to plan the integration of KM into the e-training technology in the study. Rao (2005) defines knowledge management (KM) as a systematic discipline and set of approaches to enable information and knowledge to grow, flow, and create value in an organization. This involves people, information, workflows, enabling tools, best practices, alliances, and communities of practice.

Marquadt (1996) divides KM system into four subsystems: (i) knowledge acquisition, an activity involving scanning the environment within and outside the organization for information and knowledge (explicit and tacit), (ii) knowledge creation, an activity that enables us to process and analyze information through the use of various tools, (iii) knowledge storage, an activity involving nerve in the knowledge management system that enables learners, trainers, trainees or employees to retain and retrieve knowledge and databases, and (iv) knowledge 
transfer and utilization subsystem that allow information and knowledge to be disseminated and shared. These four KM components were embedded into the conceptual framework of the study as shown in Figure 1.

The study involves a knowledge management system that gathers, organizes, shares and analyses its internal knowledge in terms of web resources, electronic and print media, archives of articles and online seminars conducted in current and previous training courses using the computer education blog to link up to various learning management systems and a localized computer-mediated communication (CMC) system. The current KM system consists of the course blog (Figure 2) that is linked to the university's Learning Management System provided by the Computer Centre and the WordPress open source blogging platform plus various other supplementary resources such as the three instructional media mentioned earlier which are a course handbook (Figure 3), an e-book on e-training (Figure 4), the computer education series (Figure 5), a number of students' moblogs which are linked to the main computer education moblog and various other resources on the web (Figure 6). The students' moblogs consist of reflections that help the coordinator of the course to make her own reflection in order to improve delivery of the course. Thus, this study aims to develop a model that shows the relationship of hybrid e-training, meaningful learning and learning style preferences.

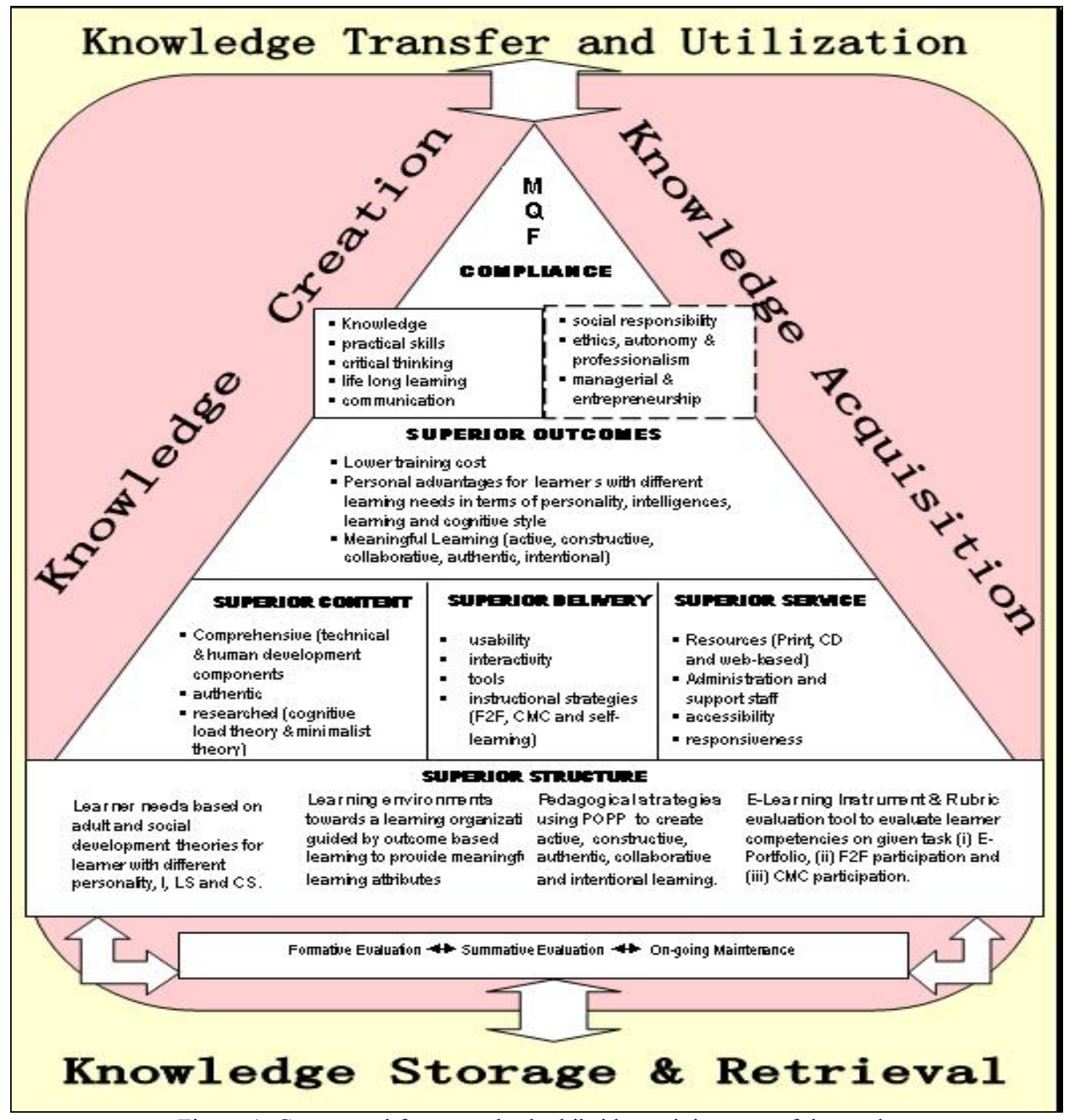

Figure 1. Conceptual framework: the hibrid e-training part of the study 


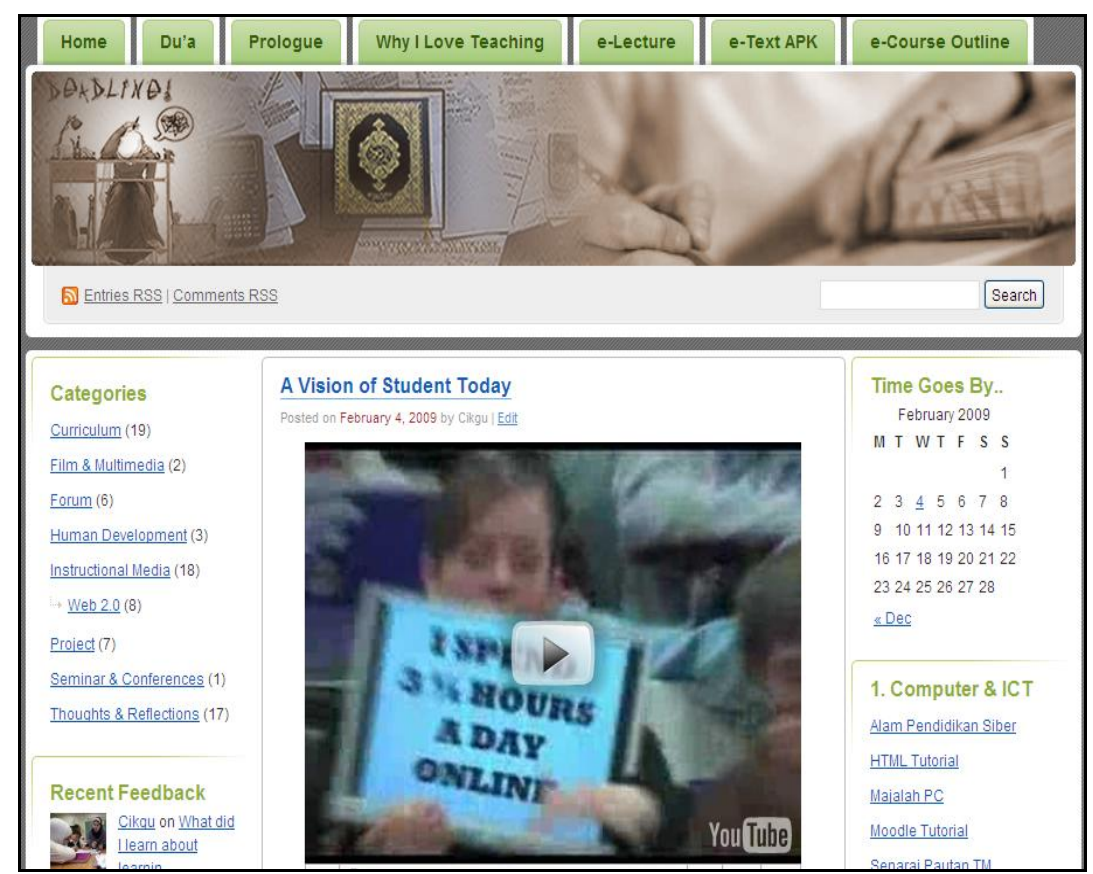

Figure 2. The course mobile blog at http://rosseni.wordpress.com

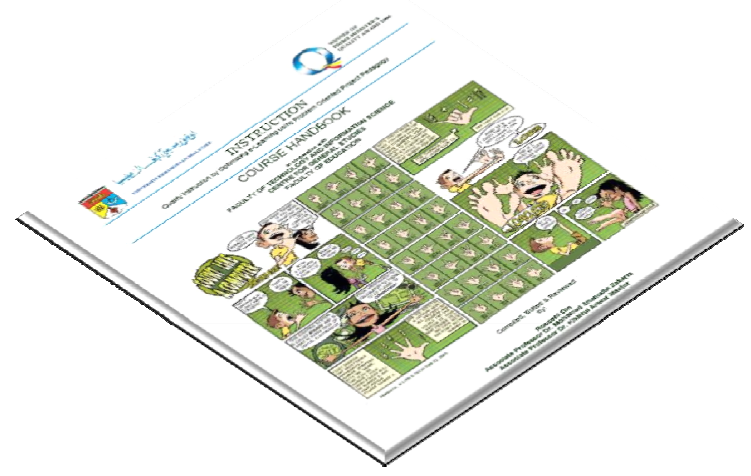

Figure 3. A handbook for computer training delivery course

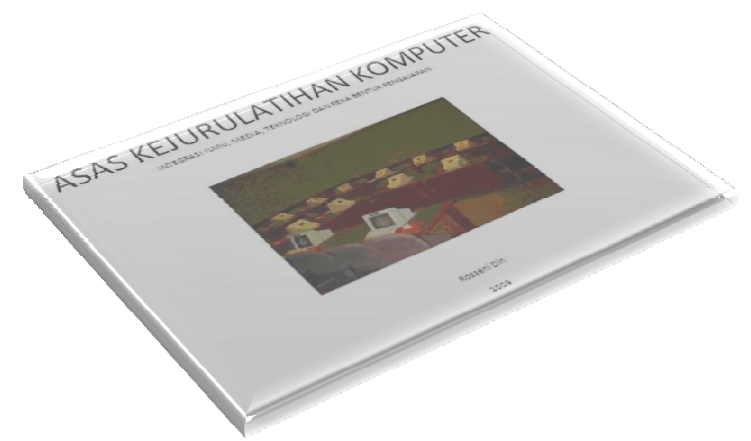

Figure 4. A supplementary e-Book on the foundation of computer training 


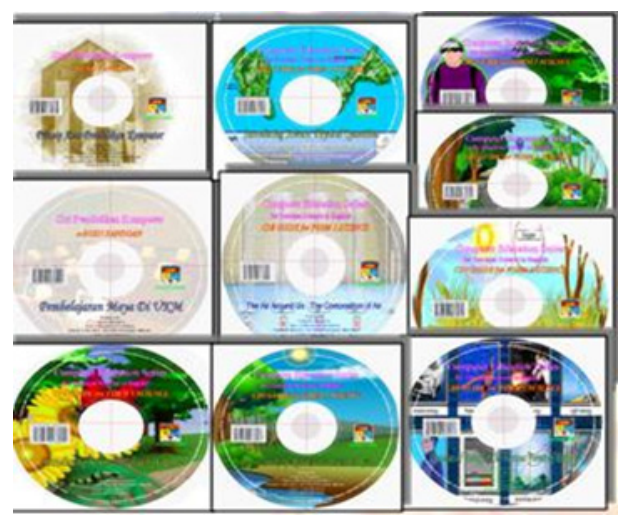

Figure 5. A computer education series for integrating technology in education

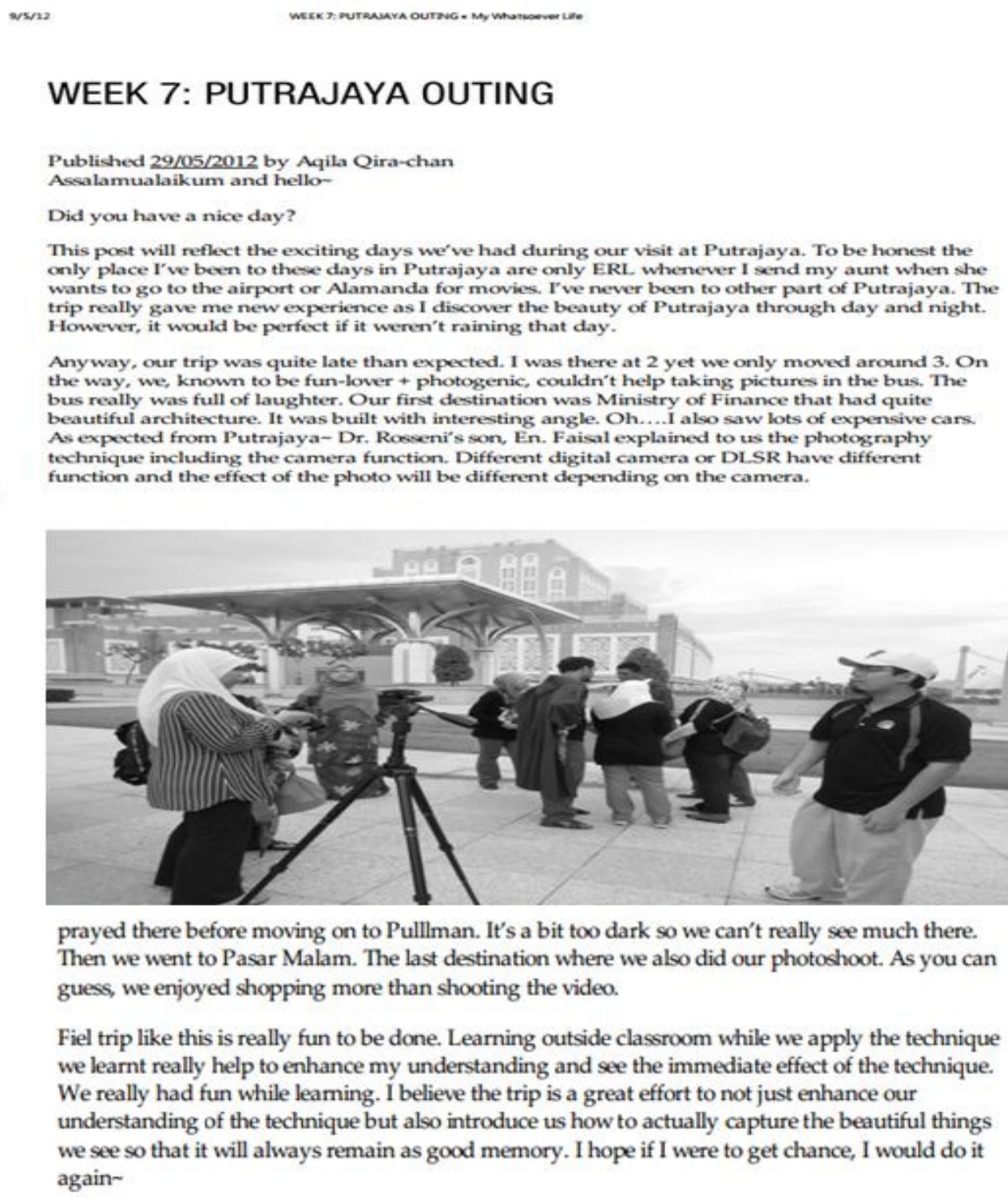

prayed there before moving on to Pullman. It's a bit too dark so we can't really see much there. Then we went to Pasar Malam. The last destination where we also did our photoshoot. As you can guess, we enjoyed shopping more than shooting the video.

Fiel trip like this is really fun to be done. Learning outside classroom while we apply the technique we learnt really help to enhance my understanding and see the immediate effect of the technique. We really had fun while leaming. I believe the trip is a great effort to not just enhance our understanding of the technique but also introduce us how to actually capture the beautiful things we see so that it will always remain as good memory. I hope if I were to get chance, I would do it again -

Figure 6. Positive and negative student's reflection from student's individual blog

\section{Method: The Iterative Triangulation Participatory Design \& Validation Method}

Research design constitutes guidelines one can use to collect, analyze, and interpret data using quantitative and qualitative approaches (Cresswell, 2005). Good research is guided by particular paradigms within which it 
operates. According to Trochim (2000), research design provides the glue that holds the research project together. As such, an iterative triangulation participatory design and validation method is used to structure the research, to show how all of the major parts of the research project - the respondents, the system, the measures - work together to try to address the central research questions.

Subsequently, alignment with a specific research paradigm is necessary. This is because it will help establish the criteria according to which one selects and defines problem and how one approaches them theoretically and methodologically (Husén, 2004) as well as the worldview that one adopts (Gay \& Airasian, 2000). In regards to computer education, computer science or technology in educational research, Keeves (2004) argues that the various research paradigms engaged are complementary to each other and that the nature of research procedures used in educational research is multidisciplinary and multimethod. Hence, no single method of inquiry should be used in educational research. It has also been argued that the emphasis given to a particular paradigm depends on the objective of the particular study (Gay \& Airasian, 2000; Husén, 2004).

This study shares a similar perspective. Nevertheless, a typology of this study into a particular research framework is made to allow for its method of inquiry and worldview to be made explicit. Broadly speaking, this study can be described as a model development research as its primary objective. In relevance to that, system design, development and validation of instruments and models were done in order to achieve the primary objective. The method used in this research will subsequently be referred to as the iterative triangulation participatory design and validation method or in short the Participatory Design (PD) method.

PD is a design method recognized for involving users as co-designers in all stages of design work. PD is based on the premise that people who are affected by a decision should have an opportunity to influence it (Schuler $\&$ Namioka, 1993: xii). As such, before getting to the model developmental process, the study built various types of instructional media, testing and evaluation instruments for the Integrated Meaningful Hybrid e-Traning (I-MeT) System implementation. Before the implementation process took place, the validation of the instrument used to measure the training program was conducted. This was done in order to provide evidence on the efficacy of the hybrid e-training method towards achieving a meaningful learning experience. In a nutshell, this study adopted mainly a quantitative research approach although in some parts during the early and final phases of the study, the qualitative approach was employed. Figure 7 shows the six phases of the research design. Figure 8 illustrates the overall picture of the design, development and validation of the I-MeT system using participative design and validation method. Figure 9 illustrates the zoom-in flow of stage 1-4 processes while Figure 10 illustrates the zoom-in flow of stage 5-6 processes. 


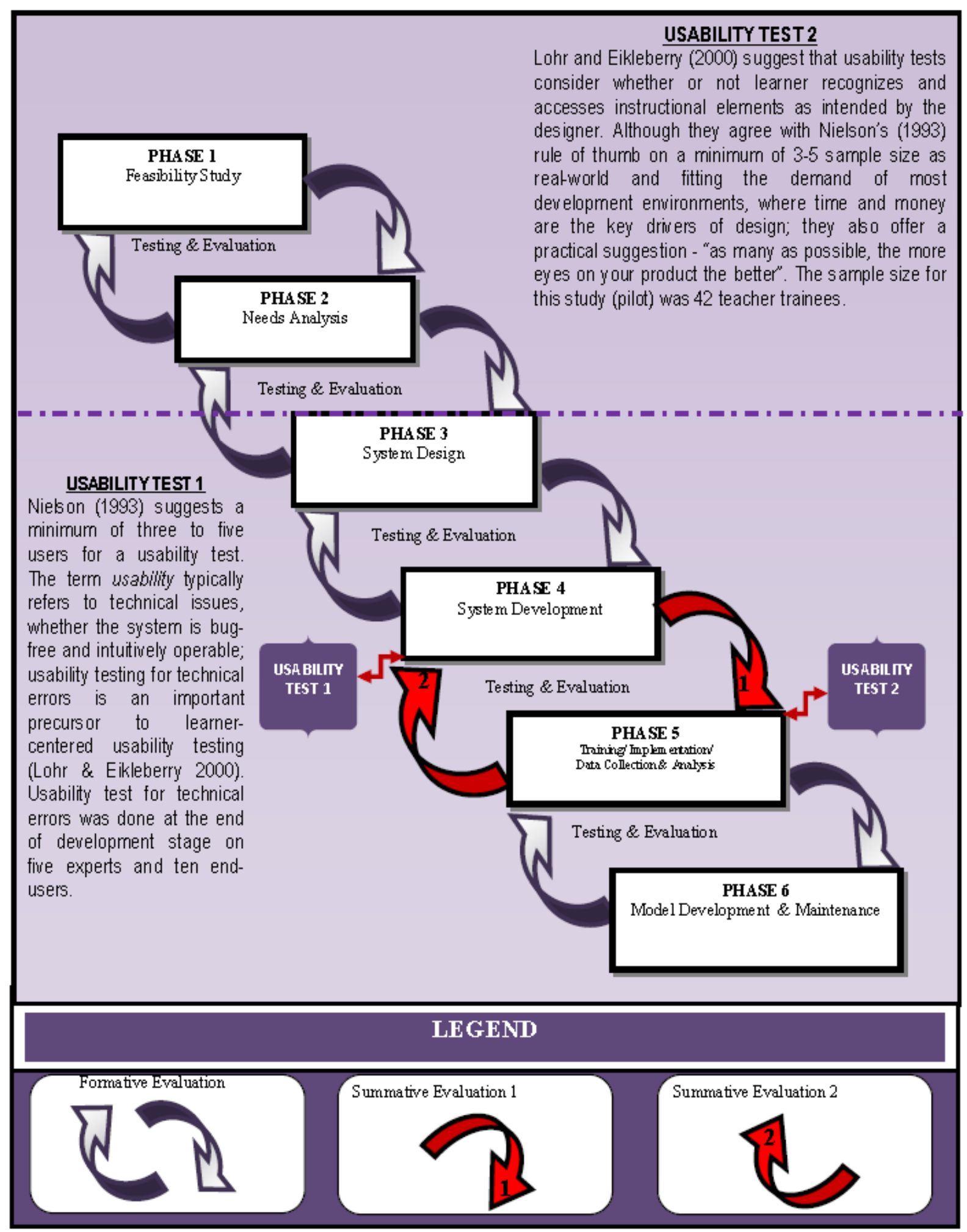

Figure 7. The instructional design, development, implementation, testing, evaluation and model development processes of I-MeT 


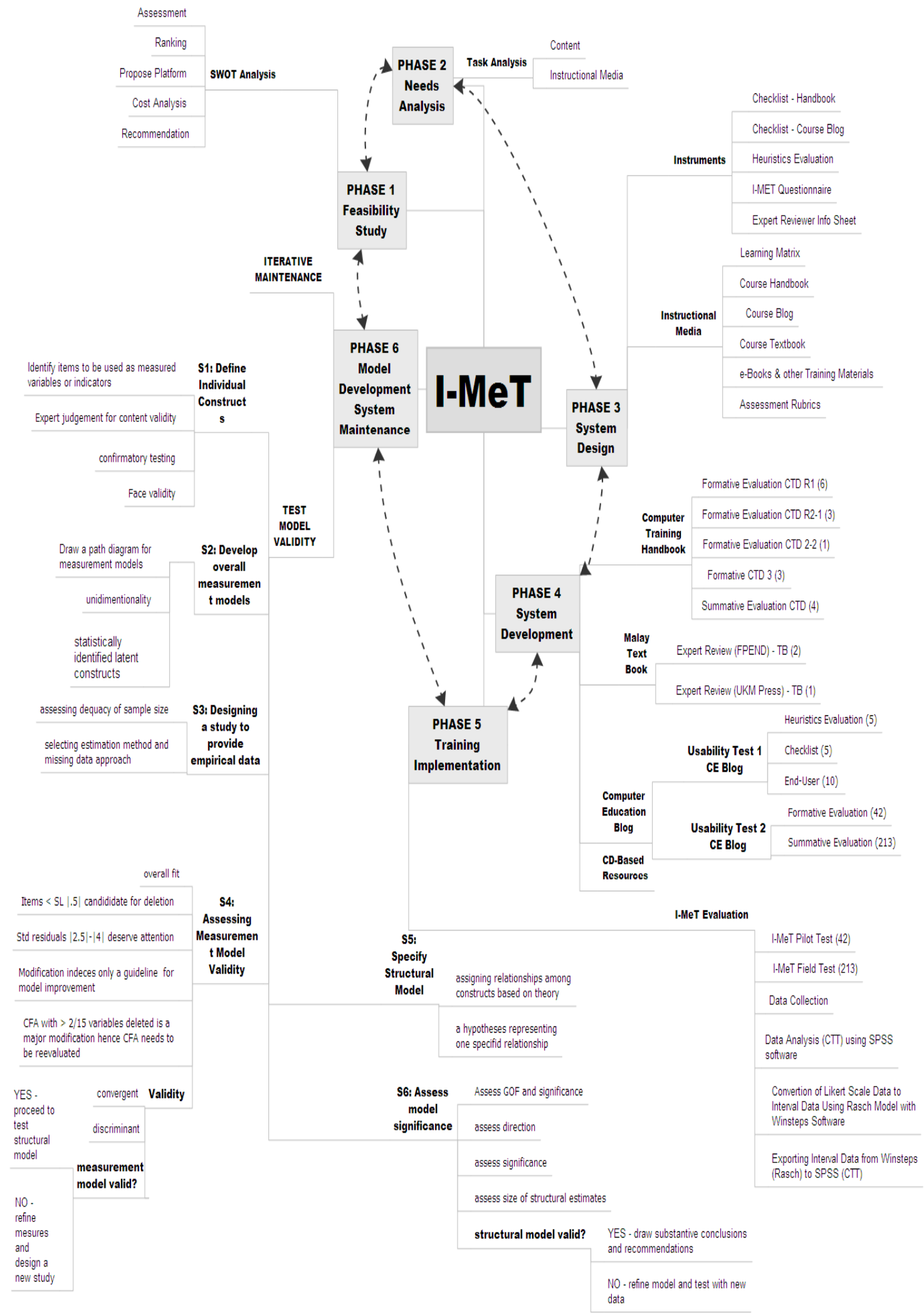

Figure 8. Iterative triangulation-participative design and validation method 


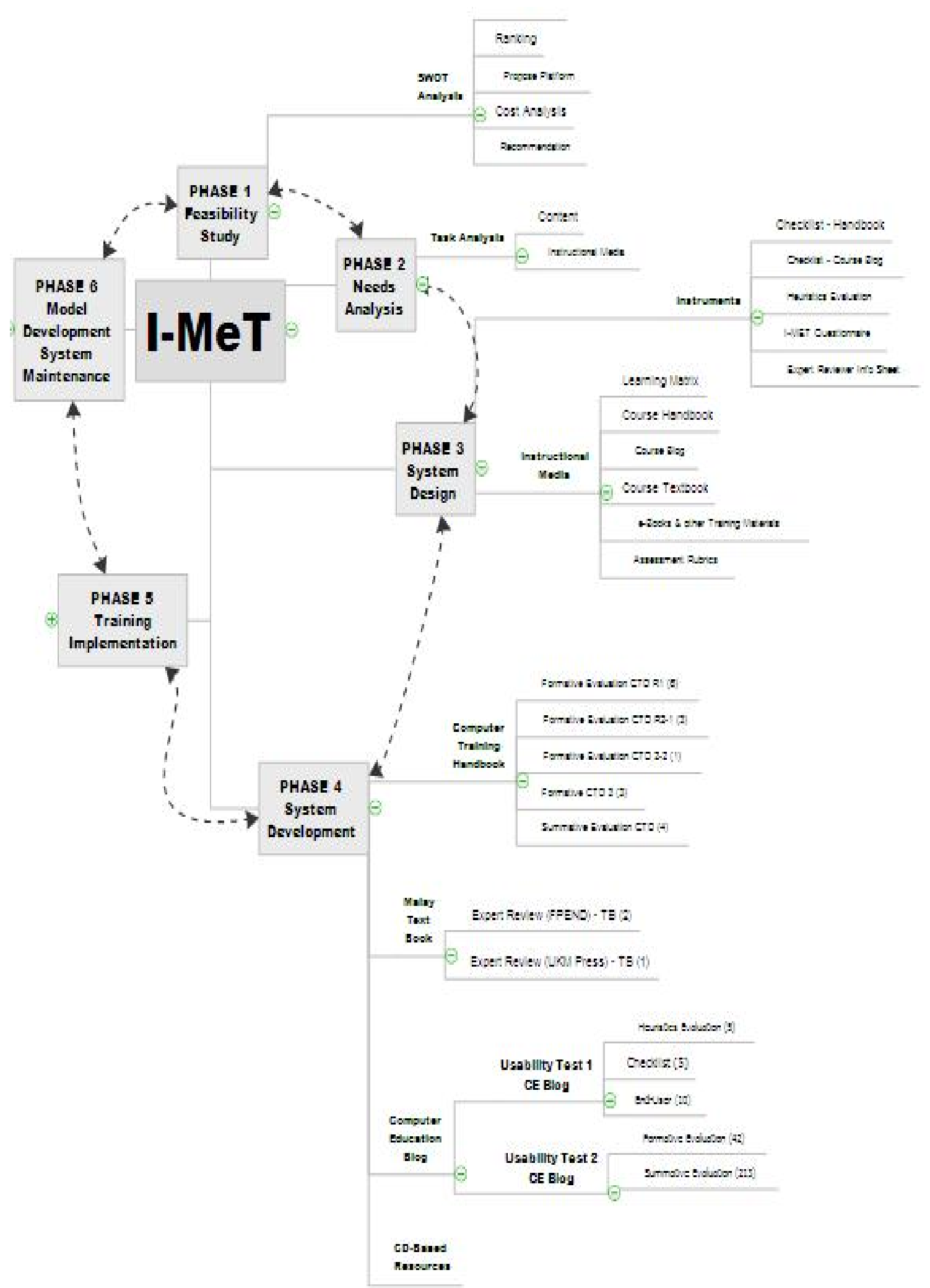

Figure 9. Iterative triangulation-participative design and validation of I- MeT phase 1-phase 4 


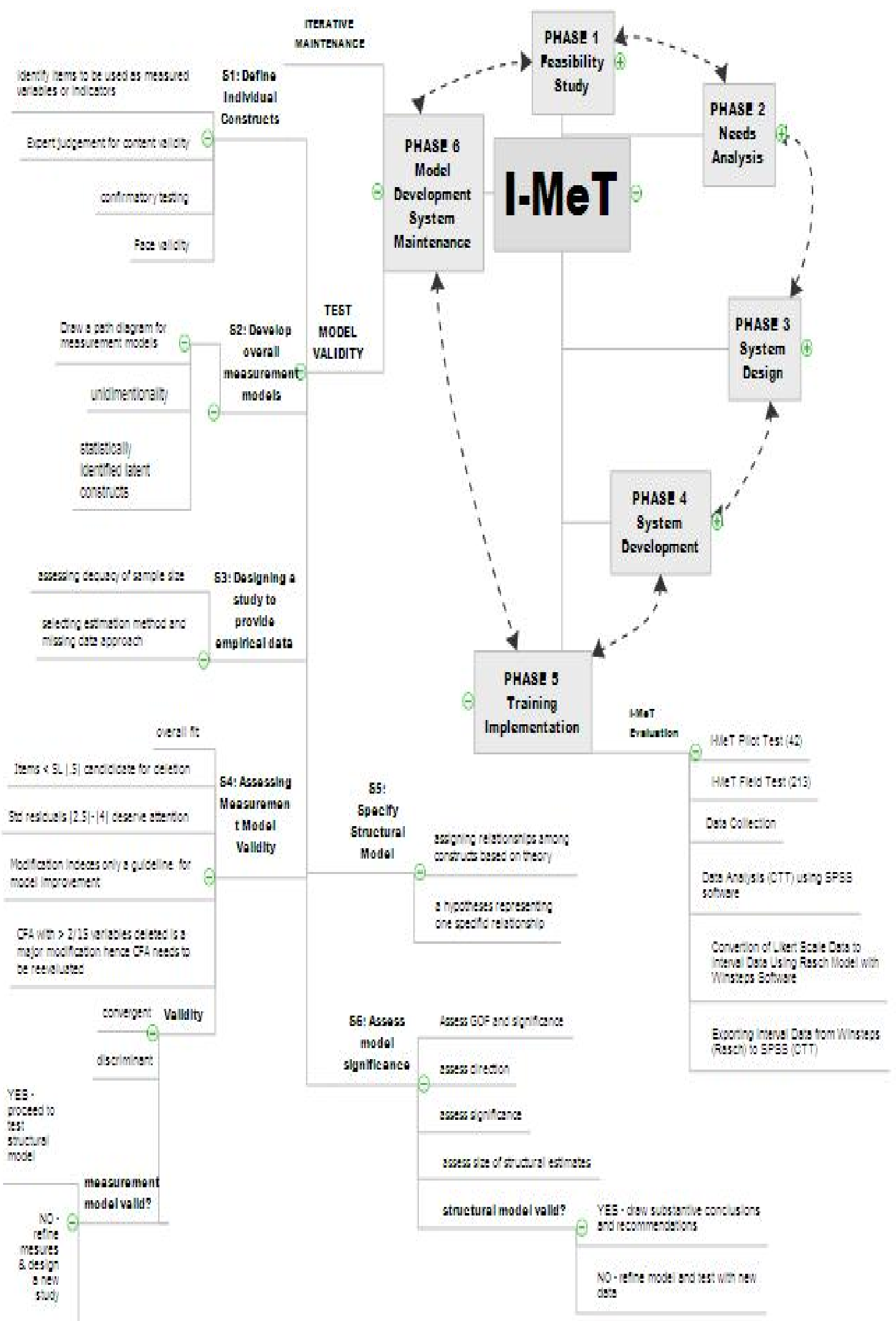

Figure 10. Iterative triangulation-participative design and validation of I-MeT phase 4-phase

\section{Sample and Research Respondents}

This study employed the structural equation model (SEM). As stated by Kline (2005), SEM is a large-sample technique that requires large sample sizes. Many factors, including the type of estimation algorithm used in the 
analysis, affect sample size requirements. In general, sample sizes of less than 100 would be considered "small", between 100-200 cases, considered "medium" and sample sizes that exceed 200 cases could be considered "large" (Kline, 2005). As with any statistical method, the critical question is how large a sample is needed. Bentler and Chou (1987) suggest that in SEM, the sample size requirements vary for measurement and structural models. In an ideal case, the following Bentler and Chou's (1987) rules of thumb need to be satisfied in order to test measurement and structural models as explained in the subsequent sections.

\section{Measurement Models}

A ratio of ten responses per free parameter is required to obtain trustworthy estimates (Bentler \& Chou, 1987). Others suggest a rule of thumb of ten subjects per item in scale development is prudent (Flynn \& Pearcy, 2001). However, if the data are found to violate multivariate normality assumptions, the number of respondents per estimated parameter increases to 15 (Bentler \& Chou, 1987; Hair, Black, Babin, Anderson \& Tatham, 2006). In this research, each of the constructs to be measured had five to six indicators, i.e. ten to twelve parameters. Applying Bentler and Chou's 10:1 rule of thumb, a sample size of 100 to 120 was required. Applying Flynn and Pearcy's (2001) rule of thumb, a sample size of 50 to 60 would suffice. Thus in terms of sample size, the study, met these requirements. To ensure a large sample size as suggested by Kline (2005), a total of 213 respondents were engaged in the study.

\section{Instrument and Data}

A survey questionnaire namely the Integrated Meaningful Hybrid e-Training Instrument (I-MINT) version 5.2 was used as the major instrument in this study to empirically test all three hypothesized relationships. The I-MINT questionnaire, contains four sections (Section A to Section D). Section A contains demographic items such as academic qualification, gender, and ethnic, age, teaching experience, country of origin and study program. Section B contains items for the meaningful e-training (MeT) measure. Section C contains items for the hybrid e-training (HiT) measure, and sections D contains items for the measure of learning preference (LSP).

\section{Results: Measure of the Integrated Meaningful Hybrid E-Training (I-MeT) Model}

This section presents the empirical results of the structural equation modeling analysis for the testing of hypotheses, proposing models for testing the underpinning theories and validating those models. This section also concludes the overall SEM findings. The section reports how structural equation modeling (SEM) was used in the study to test the three hypotheses in relation to the three latent variables. This section reports the results of the investigations about the relationships among hybrid e-training system (HiTs), meaningful e-training (MeT) and learning style preference (LSP). To support the investigation, the following hypotheses were tested,

$$
\begin{aligned}
& \mathrm{H}_{01} \text { : HiT does not influence the achievement of MeT. } \\
& \mathrm{H}_{02} \text { : LSP does not influence the acceptance of HiT. } \\
& \mathrm{H}_{03} \text { : LSP does not influence the achievement of MeT. }
\end{aligned}
$$

A hypothesized structural model was constructed in the second stage of the overall SEM analysis process. A visual diagram depicting the first hypothesized structural model for this relationship with the tested parameters is shown in Figure 11. To validate the likelihood of the revised three-construct model, several rounds of SEM analysis were applied on the same sample. The tested hypothesized model and the final revised model are shown in Figures 11 and 12 respectively. The overall fit of the final revised model is summarized in Figure 12. 


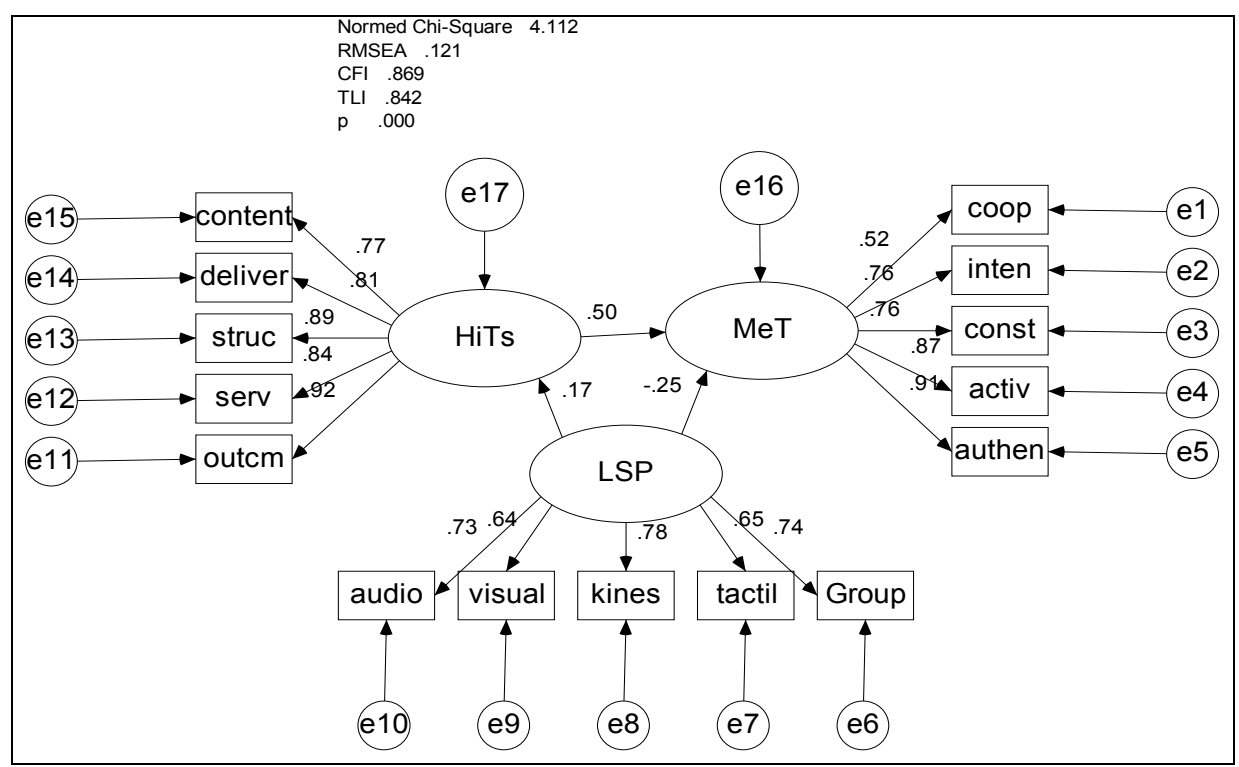

Figure 11. Results of the hypothesized structural relationships among HiTs, MeT and LSP

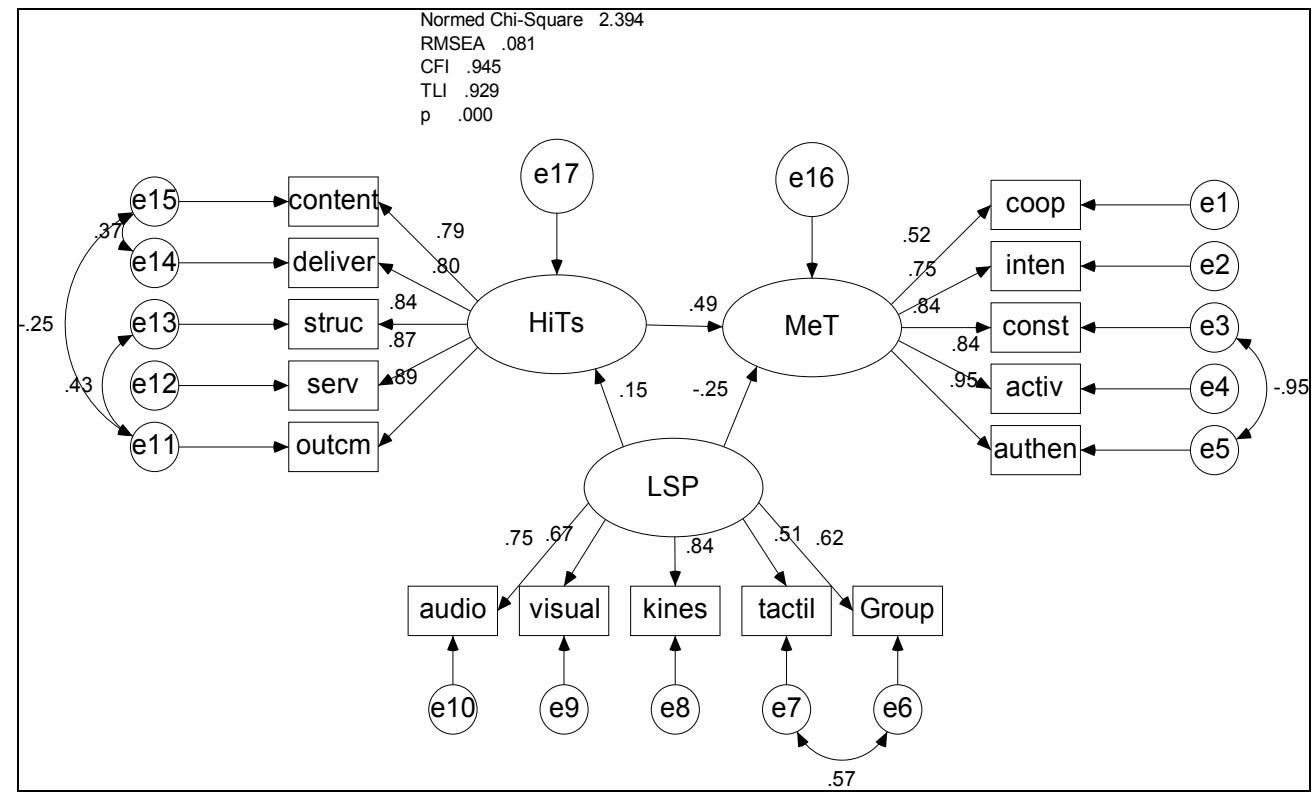

Figure 12. Results of structural relationships among HiTs, MeT and LSP

To support the investigations the following hypotheses were tested, and the results of the hypothesis tests are concluded as follows.
$\mathrm{H}_{01}$ : HiT does not influence the achievement of MeT. Reject
$\mathrm{H}_{02}$ : LSP does not influence the acceptance of HiT. Reject
$\mathrm{H}_{03}$ : LSP does not influence the achievement of MeT. Reject

The factor loadings in the final revised model were substantially significant with CFI $=.945$, TLI $=.929$ and RMSEA $=.081$. The statistics indicate that the parameters were free from offending estimates, ranging from .52 to .95. The CFI (.945) and TLI (.929) fit indicators exceeded the threshold of .90, indicating a very good fit. The root-mean square error of approximation $(\mathrm{RMSEA}=.081)$ met the cut-off point requirement for a reasonable error of approximation (Hair et al. 2006). The normed chi-square $\left(\chi^{2}\right)$ of 2.471 for a good fit was also met. The final fit index indicates that the test rejected the hypothesized model. As such, the researcher concluded the model in Figure 12 to be the validated structural equation model for integrated meaningful hybrid e-training. Therefore, hypothesis testing rejected the three statements (HiT does not influence MeT; LSP does not influence HiT; LSP does not influence MeT). 


\section{Conclusion}

This paper has presented the integrated meaningful e-training system represented by various instructional media with the mobile blog being the main delivery and computer mediated communication between learners and facilitators. A representative of the system shown earlier was a sample reflection from a student's blog about the implementation of the course using the system. The results shown in the final model as in Figure 12 indicate that the empirical evidence generated from the measurement of constructs is consistent with the theoretical logic of the concepts under study.

\section{References}

Bentler, P. M., \& Chou, C. P. (1987). Practical issues in structural modeling. Sociological Methods \& Research. 16(1), 78-117. http://dx.doi.org/10.1177/0049124187016001004

Cresswell, J. W. (2005). Educational Research: Planning, Conducting and Evaluating Quantitative and Qualitative Research (2nd ed.). New Jersey: Prentice Hall.

Flynn, L. R., \& Pearcy, D. (2001). Four subtle sins in scale development: Some suggestions for strengthening the current paradigm. International Journal of Market Research, 43(4), 409-423.

Gay, L. R., \& Airasian, P. (2000). Educational research: Competencies for analysis and application (6th ed.). Upper Saddle River, NJ: Merrill \& Prentice-Hall.

Hair, J. F., Black, W. C., Babin, B. J., Anderson, R. E., \& Tatham, R. L. (2006). Multivariate data analysis (6th ed.). Upper Sadle, New Jersey: Pearson Prentice Hall.

Husén, T. (2004). Research paradigms in education. In J.P. Keeves (Ed.), Educational research, methodology, and measurement: An international handbook (2nd ed.). Oxford, UK: Elservier Science Ltd.

Keeves, J. P. (2004). Introduction: Towards a unified view of educational research. In J. P. Keeves (Ed.), Educational research, methodology, and measurement: An international handbook (2nd ed.). Oxford, UK: Elservier Science Ltd.

Kline, R. B. (2005). Principles and practice of structural equation modeling (2nd ed.). New York: Guildford Press.

Marquadt, M. J. (1996). Building the learning organization. New York: McGraw- Hill.

Rao, M. (2005). Overview: the social life of KM tools. Rao, M. In Knowledge Management Tools and techniques: practitioners and experts evaluate KM solutions. Boston: Elsevier Butterworth-Heinemann.

Santosus, M., \& Surmacz, J. (2001). The ABC's of knowledge management. CIO Magazine. Retrieve May 30, 2005, from http://www.cio.com/research/knowledge/edit/kmabcs.html

Schuler, D., \& Namioka, A. (Eds.). (1993). Participatory Design: Principles and Practices. New Jersey: Lawrence Erlbaum Associates, Publishers.

Trochim, W. (2000). The Research Methods Knowledge Base (2nd ed.). Cincinnati, OH: Atomic Dog Publishing. 